\title{
Using small drones to photo-identify Antillean manatees: a novel method for monitoring an endangered marine mammal in the Caribbean Sea
}

\author{
Sarah Sofía Landeo-Yauri ${ }^{1, *}$, Eric Angel Ramos ${ }^{2,3}$, \\ Delma Nataly Castelblanco-Martínez ${ }^{2,4,5}$, Carlos Alberto Niño-Torres ${ }^{2,5}$, Linda Searle ${ }^{6}$ \\ ${ }^{1}$ Posgrado de Ciencias del Mar y Limnología, Universidad Nacional Autónoma de México, Ciudad de México 04510, Mexico \\ ${ }^{2}$ Fundación Internacional para la Naturaleza y la Sustentabilidad, Chetumal 77014, Mexico \\ ${ }^{3}$ The Graduate Center, City University of New York, New York, NY, 10016, USA \\ ${ }^{4}$ Consejo Nacional de Ciencia y Tecnología, Ciudad de México 03940, Mexico \\ ${ }^{5}$ Universidad de Quintana Roo, Chetumal 77039, Mexico \\ ${ }^{6}$ ECOMAR, PO Box 1234 Belize City, Belize
}

\begin{abstract}
Population assessments and species monitoring for many endangered marine megafauna are limited by the challenges of identifying and tracking individuals that live underwater in remote and sometimes inaccessible areas. Manatees can acquire scars from watercraft injury and other incidences that can be used to identify individuals. Here we describe a novel method for photo-identification of Antillean manatees Trichechus manatus manatus using aerial imagery captured during flights with a small multirotor drone. Between 2016 and 2017, we conducted 103 flights to detect and observe manatees in Belize, primarily at St. George's Caye (SGC) near the Belize Barrier Reef. Review of aerial videos from these flights resulted in 279 sightings of manatees ( 245 adults, 34 calves). High-resolution images of individual manatees were extracted and classified according to image quality and distinctiveness of individual manatees for photoidentification. High-quality images of manatees classified as sufficiently distinctive were used to create a catalog of 17 identifiable individuals. At SGC, $21 \%$ of all sighted adult manatees $(\mathrm{N}=214)$ were considered photo-identifiable over time. We suggest that the method can be used for investigating individual site fidelity, habitat use, and behavior of manatee populations. Our photoidentification protocol has the potential to improve long-term monitoring of Antillean manatees in Belize and can be applied throughout clear, shallow waters in the Caribbean and elsewhere.
\end{abstract}

KEY WORDS: Drones $\cdot$ Trichechidae $\cdot$ Photo-ID $\cdot$ Manatee $\cdot$ Trichechus manatus manatus

\section{INTRODUCTION}

The Antillean manatee Trichechus manatus manatus is a subspecies of the West Indian manatee $T$. manatus and is considered Endangered by the IUCN (Self-Sullivan \& Mignucci-Giannoni 2008) due to threats such as entanglement, poaching, watercraft collision, and habitat loss (Castelblanco-Martínez et al. 2012). In the Regional Management Plan for the

\footnotetext{
${ }^{*}$ Corresponding author: sslandeo@gmail.com
}

West Indian manatee (Quintana-Rizzo \& Reynolds 2010), long-term and longitudinal studies of individually identifiable animals are recommended to determine the survival rates, reproduction rates, site fidelity, and movement patterns of manatee populations. However, the techniques typically used to identify individuals, such as capturing and tagging animals, are expensive, invasive, and require extensive effort. Devising affordable alternative methods

() The authors 2020. Open Access under Creative Commons by Attribution Licence. Use, distribution and reproduction are unrestricted. Authors and original publication must be credited. 
for tracking manatees in regions with limited available research funds is essential to the species' longterm preservation (Quintana-Rizzo \& Reynolds 2010).

Photo-identification (photo-ID) is typically the most affordable and non-invasive method to identify individual animals using unique features on the surface of an animal's body (Würsig \& Würsig 1977, Gope et al. 2005). Photo-ID methods are often used during the monitoring of most whale and dolphin populations to distinguish individuals through comparisons of the scarring patterns and unique markings on the dorsal fins, flukes, or body surfaces to catalogs of previously identified individuals (Urian et al. 2015). In sirenians, studies employing photo-ID have been conducted on dugongs Dugong dugon (Shawky et al. 2017) and West Indian manatees (Beck \& Reid 1995) using surface scarring patterns to distinguish animals, and with Amazonian manatees T. inunguis using the light-colored ventral patch of most individuals of this species (Ely et al. 2017). Images of animal scarring and identifying marks are typically gathered with high-resolution cameras from boats (Reid et al. 1991, Anderson 1995, Langtimm et al. 2004), shore (Reid et al. 1991, Langtimm et al. 2004, Goldsworthy 2018), underwater photographs (Langtimm et al. 2004, Shawky et al. 2017) and underwater videos (Arce 2012), or during captures for health assessments (Stamper \& Bonde 2012). Sirenians often bear scars, mutilations, and congenital deformities on their bodies that are stable enough to reidentify individuals over time (Beck \& Clark 2012). For example, cuts from boat propellers are a common cause of scars in T. manatus (Beck et al. 1982, Self-Sullivan 2007), whereas D. dugon scarring can also be attributed to wounds inflicted by tusks of adult males (Anderson 1995). Photo-ID data have enabled the investigation of important demographic factors of Florida manatees T. m. latirostris, such as reproductive rates (Kendall et al. 2004), annual adult survival rates (Langtimm et al. 1998, 2004), reproduction traits (Rathbun et al. 1995), and movement patterns (Reid et al. 1991). Criteria that must be considered for successful photo-ID of sirenians include: (1) imaged individuals must have at least 1 permanent feature (e.g. scar, mutilation); (2) good quality images depicting the feature should be obtained; and (3) images of the entire body must be available (Beck \& Reid 1995). These criteria help ensure that all permanent body marks are detected and that the individual can be identified over time and in different areas.

In the Caribbean Sea, capturing images of wild manatees is challenging due to the small size and low density of their populations (Quintana-Rizzo \& Reynolds 2010). Manatees are often found alone or in groups of fewer than 10 individuals (Hartman 1979). In contrast, large aggregations of manatees $(>100)$ like those documented during the winter season in Florida, USA, provide more opportunities for obtaining high-quality photographs of individuals with distinct features (Beck \& Reid 1995). Additionally, their shy and inconspicuous behavior, minimal time at the surface (Hartman 1979), strong responses to oncoming vessels (Rycyk et al. 2018), and sometimes to swimmers (D.N.C.-M. pers. obs.), can make it difficult to find manatees and to approach them to detect body scars and identifiable features at the surface.

Manned aerial surveys are commonly used to remotely detect and study sirenians (e.g. Ackerman 1995, Marsh 1995, Morales-Vela et al. 2003, Alves et al. 2016) and many other species of marine mammal (e.g. Bengtson et al. 2005, Keller et al. 2006, Panigada et al. 2011) because aerial surveys provide overhead views which facilitate the detection and counting of individuals. In recent years, unmanned aerial systems or drones have demonstrated their use in supplementing, or in some contexts, replacing, manned aerial surveys (Hodgson et al. 2013). Drones possess several major advantages over manned aerial surveys: they can record detailed flight logs and permanent visual records, are safer for the operator, and can be less costly than manned aerial surveys (Hodgson et al. 2013). Manned aerial surveys can cover larger areas and fly longer compared to small drones, but lack the maneuverability of multirotor drones and the potential of drones for extensive sampling in small areas and at low altitudes (Colefax et al. 2018). Drones have been successfully used in a broad range of applications including the detection and counting of marine megafauna (Hodgson et al. 2017); photogrammetry to assess cetacean body condition (Durban et al. 2015, 2016, Christiansen et al. 2016); collection of exhaled breath condensate from large baleen whales (Domínguez-Sánchez et al. 2018), and behavioral studies (Ramos et al. 2018, Torres et al. 2018). Drone-based photo-ID studies of bowhead whales Balaena mysticetus (Koski et al. 2015), killer whales Orcinus orca (Durban et al. 2015), and seals (Pomeroy et al. 2015) have confirmed the efficacy of this method for identifying numerous marine mammals, but its application to sirenians has not been thoroughly examined.

Photo-ID of sirenians with drone-based imagery is a promising avenue of research. To our knowledge, Ramos et al. (2018) conducted the only study to date that tested the use of small drones for photo-ID of manatees, but a description and validation of the method has not been made until now. Here we used 
part of the same dataset as Ramos et al. (2018) to describe and examine the efficacy of a novel method using small drones to photo-identify Antillean manatees. Images of all manatee sightings were extracted from aerial videos, selected according to image quality as well as distinctiveness of manatee features, and used to identify and catalog distinctive individuals. Our proposed photo-ID method has promise as a lowcost aerial platform to improve the capacity for monitoring and researching wild manatee populations in the Caribbean.

\section{MATERIALS AND METHODS}

\subsection{Study area}

The coast of Belize is comprised of a diverse array of marine ecosystems and habitats, including sandy and mangrove cayes, coastal lagoons, estuaries, and a system of fringing reefs of the Mesoamerican Barrier Reef System and 3 offshore atolls (Cho 2005). Important areas for manatees include the cayes adjacent to Belize City, the Belize River, the Southern Lagoon, Placencia Lagoon, Corozal Bay Wildlife Sanctuary, and the Port Honduras area (Auil 1998).

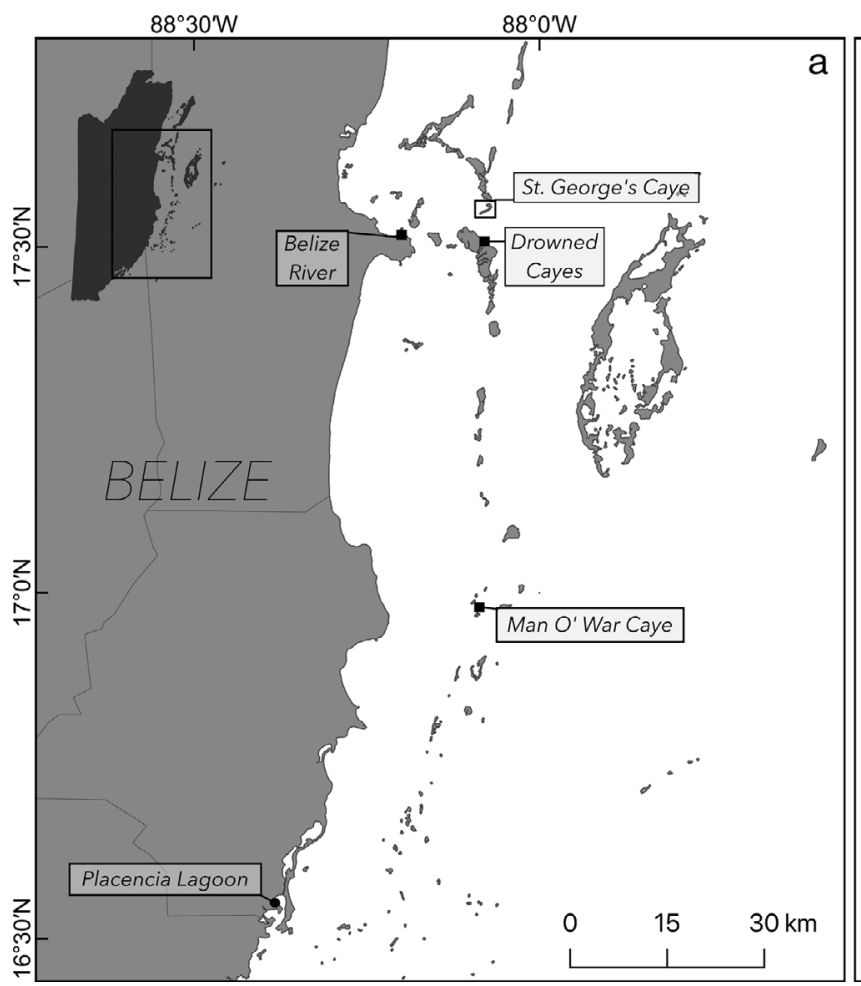

Drone flights were conducted from June to July 2016 and July 2017 at St. George's Caye (SGC), a small crescent-shaped island located $10 \mathrm{~km}$ east of Belize City and $1.5 \mathrm{~km}$ west of the Belize Barrier Reef (Fig. 1). Extensive seagrass flats and calm waters prevail on the leeward side of the island, and mixed seagrass/sand patches and a sandbar on the windward side. Opportunistic surveys were also performed at the mouth of the Belize River, the Drowned Cayes, Man O' War Caye, and in Placencia Lagoon (Fig. 1).

\subsection{Drone flights}

Our protocol for drone flights corresponds to that of Ramos et al. (2018), who aimed to record manatee behavior and test if manatees respond to the presence of a small drone. From these flights and associated data, we used a subset to examine their use for manatee photo-ID.

Two commercial drones, the DJI Phantom 3 Professional (P3) and Phantom 4 (P4) quadcopters, were used for flights. Each drone was equipped with a high-definition camera (1/2.3' CMOS, 12.4 MP sensor; FOV $94^{\circ} 20 \mathrm{~mm}$ f/2.8 lens) recording $4 \mathrm{~K}$ video in MP4 format, mounted to its 3-axis gimbal transmitting a live-feed to the tablet-mounted remote control. The $88^{\circ} 4.6^{\prime} \mathrm{W}$

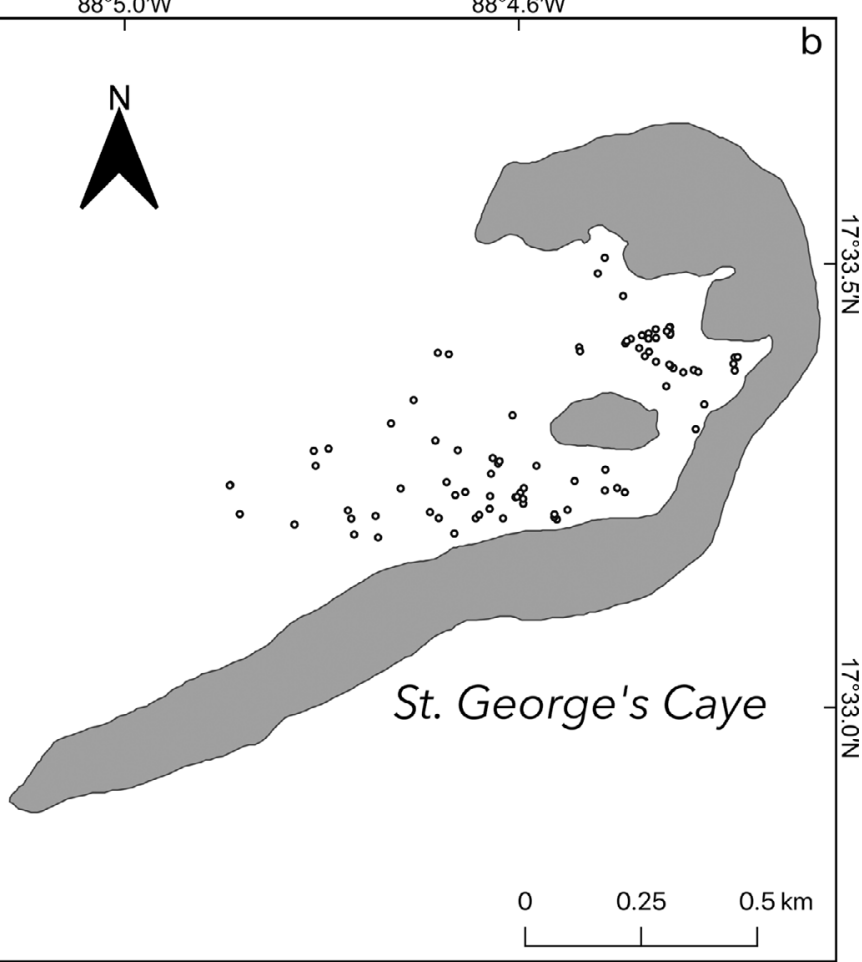

Fig. 1. (a) Study area in Belize (inset map shows the study area in relation to the whole country). Light gray lines demarcate districts. (b) Open circles represent sightings of Antillean manatees during small drone flights at St. George's Caye 
drone was remotely piloted from shore for most flights and from a small (7-13 m long) motorboat (Drowned Cayes) or a 13 m long catamaran (Man O' War Caye, Placencia Lagoon). The pilot (E.A.R.) launched the drone to an altitude of $100 \mathrm{~m}$ at the beginning of flights to search for manatees on designated transects or to perform behavioral follows of previously detected manatees. Transects were saw toothed and followed mainly the entire leeward side of the caye, covering approximately $1.6 \mathrm{~km}^{2}$.

The protocol entailed at least 1 flight $\mathrm{h}^{-1}$ (6-20 flights $\mathrm{d}^{-1}$ ) following a predetermined saw-toothed route covering the study area to determine manatee locations. In the same or following flight, prior detections of manatees were used to fly to the same spot to approach an individual manatee or group of manatees. The animals were approached in one of several ways: vertical approaches to test animal responses (ranging from 5 to $100 \mathrm{~m}$ in altitude; Ramos et al. 2018), horizontal follows, or stable hovering over animals for focal behavioral follows.

Additional flights were conducted to monitor manatee occurrence in large nearby resting holes, i.e. depressions in the substrate where manatees frequently rest and seek shelter in Belize (Bacchus et al. 2009), and to observe their behavior. During flights, binoculars were used to maintain a visual line of sight with the drone.

\subsection{Data analysis}

Each drone video was reviewed post-survey at least twice by an experienced observer. Extracted images of manatees were acquired at different altitudes depending on whether they were recorded during horizontal or vertical approaches and stable hovering. The time at which images were extracted from each video was matched to drone flight altitude in the GPS-logged track. We selected the images in which most of each individual's body was visible and clear. One to 7 high-resolution images $(3840 \times 2160$ pixels) of each manatee were extracted from videos in VideoPad v. 5.05 (NCH Software).

To standardize and facilitate the assessment of features on the manatees, images were coded, cropped, and rotated to align them lengthwise to the body of each manatee. Each image was then scored for 'quality' and 'distinctiveness.'

A preliminary sighting database was assembled including flight information: location, date, and time of video, sighting coordinates, number of manatees detected, and proportion of calves and adults. This data-
Table 1. Image quality assessment criteria for photo-ID of Antillean manatees. See Fig. 2 for representative images

\begin{tabular}{|c|c|c|}
\hline Factor & Description & Scoring \\
\hline $\begin{array}{l}\text { Resolution/ } \\
\text { clarity }\end{array}$ & Sharpness of image & $\begin{array}{l}2=\text { excellent } \\
4=\text { average (grainy) } \\
9=\text { poor (blurred) }\end{array}$ \\
\hline Contrast & $\begin{array}{l}\text { Range of tones in the } \\
\text { image }\end{array}$ & $\begin{aligned} 1= & \text { ideal } \\
2= & \text { excessive or } \\
& \text { minimal }\end{aligned}$ \\
\hline Distortion & $\begin{array}{l}\text { Portion of manatee } \\
\text { body distortedby water } \\
\text { surface movement }\end{array}$ & $\begin{array}{l}1=\text { none to little } \\
2=\text { partial } \\
8=\text { complete }\end{array}$ \\
\hline Partial & $\begin{array}{l}\text { Portion of manatee body } \\
\text { visible. Body parts can } \\
\text { be covered by turbidity } \\
\text { and/or light reflection }\end{array}$ & $\begin{aligned} 1= & \text { all body } \\
& \text { visible } \\
2= & \text { body partially } \\
& \text { visible }\end{aligned}$ \\
\hline Angle & $\begin{array}{l}\text { Angle of dorsal view } \\
\text { to camera }\end{array}$ & $\begin{array}{l}1=\text { perpendicular } \\
2=\text { moderately } \\
\text { angled }\end{array}$ \\
\hline
\end{tabular}

base was used to compile information of all sightings, irrespective of whether the animal photographed was cataloged. The geographic position (latitude and longitude) of individual manatees at the time at which they were first detected was identified by overlaying the GPS track of each flight onto an orthomosaic map of the region (see Ramos et al. 2018) in ArcGIS Pro (ESRI). The manatee's location in the video was matched to stable habitat features in the map (e.g. boat scars in the substrate, edges of seagrass beds).

A method of scoring images to evaluate the 'quality' of manatee photos was adapted from previous studies on humpback whales Megaptera novaeangliae (Friday et al. 2000) and bottlenose dolphins Tursiops truncatus (Urian et al. 1999, Rosel et al. 2011). Image quality was measured according to the following characteristics: resolution/clarity, contrast, angle, partial, and distortion (Table 1, Fig. 2). The sum of scores for each characteristic was classified for quality as excellent (Q1: score of 6-8), average (Q2: score of 9-12), or poor (Q3: score of $>12$ ).

The distinctiveness of individuals was evaluated in each image (Fig. 2), according to the following categories modified from Urian et al. (1999):

- D1(very distinctive): easily detected scars that are evident on all quality levels of image, even poor;

- D2 (average): minimal scarring that is only evident in images of quality Q1 and Q2;

- D3 (not distinctive): lacking marks or with subtle scratches and/or coloration patches that are not long-lasting and do not allow the identification to individual level. Subtle marks are likely to be visible only on Q1 quality images; 
a

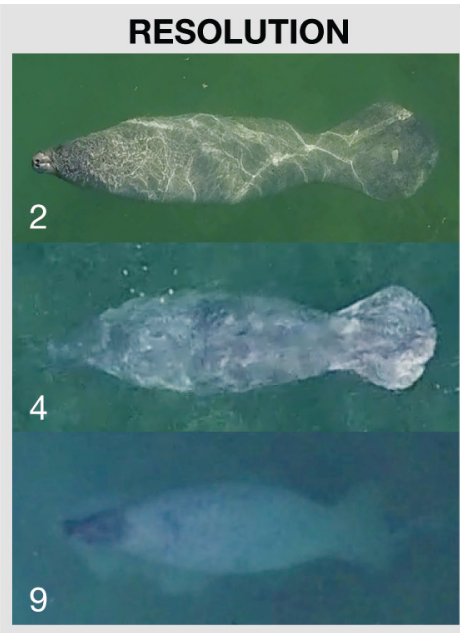

b

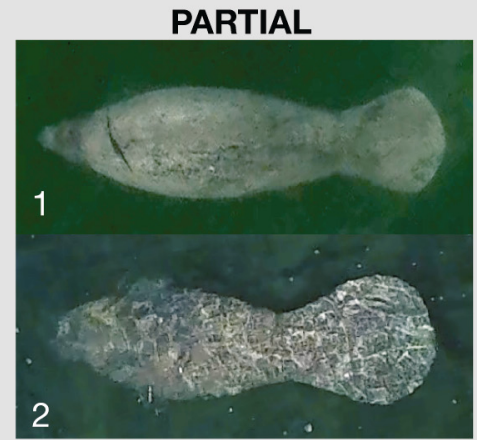

C

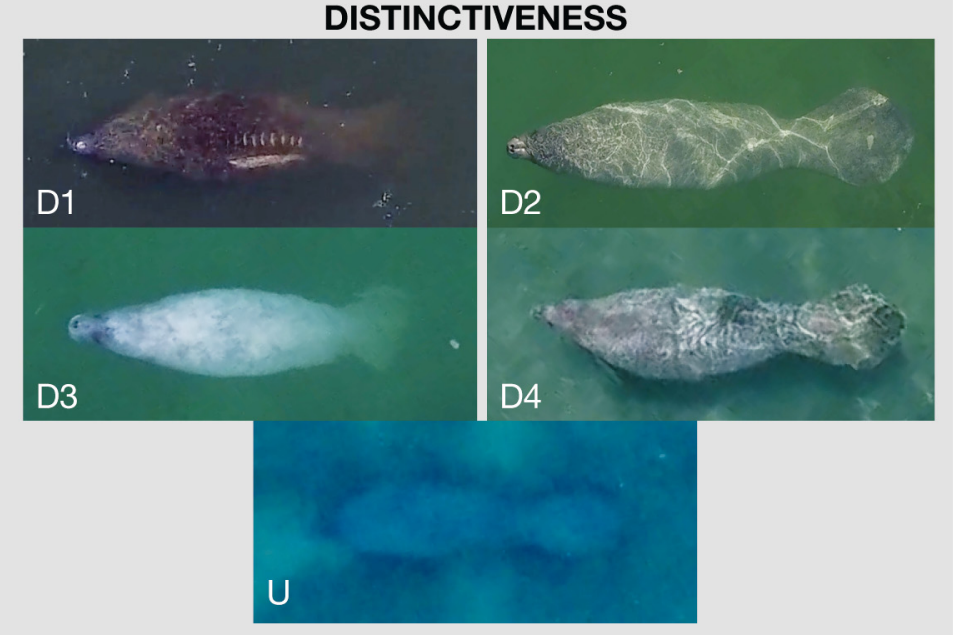

CONTRAST

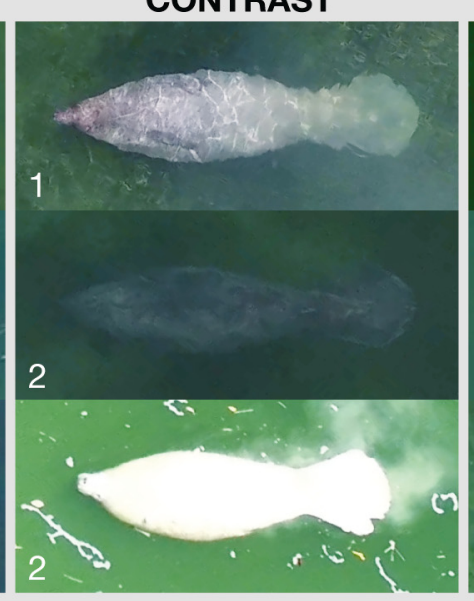

ANGLE

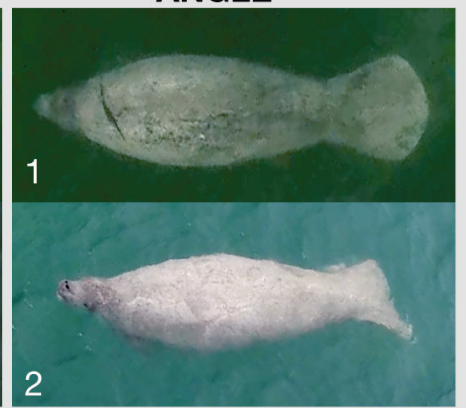

Fig. 2. Drone-based images of Antillean manatees scored for image quality assessment and distinctiveness. (a) Images in the left column represent resolution/clarity, scored as 2 (excellent), 4 (average), or 9 (poor); those in the middle column represent contrast, scored as 1 (ideal) or 2 (excessive or minimum); and those in the right column represent distortion, scored as 1 (none), 2 (partial), or 8 (absolute). (b) Images in the left column are partial, scored as 1 (whole body visible) or 2 (body partially covered by light reflection or turbidity); images in the right column show different angles, scored as 1 (perpendicular) or 2 (moderately angled). (c) Representative images scored as D1 (very distinctive), D2 (average), D3 (not distinctive), D4 (coloration pattern) and U (unknown)
- D4 (pattern): medium to large patterns of coloration, which are not long lasting and therefore do not meet the requirements for photo-dentification. Evident on all image quality levels;

- Unknown (U): a classification cannot be made, generally because of insufficient image quality.

Four authors (S.S.L.-Y., E.A.R., D.N.C.-M., C.A.N.-T.) independently reviewed the images and evaluated them for quality and distinctiveness. For each image, the quality was defined as the average of scores. Dis- tinctiveness, for which categories cannot be scored, was assigned the category selected by most evaluators. Images for which there was no consensus among evaluators were given a D3 or U category. Images classified as sufficiently distinctive for individual identification (D1 and D2) were selected regardless of their quality. From this batch, the best quality images from each identified manatee were entered into the photo-ID catalog. Images not used in the catalog were kept in separate files assigned to each 
identified manatee. Fig. 3 depicts the data processing workflow from capture of aerial video of manatees from flights with a small drone, through image analysis and the creation of a photo-ID catalog.

\subsection{Cataloging and sighting index}

We assigned an alpha-numeric code and a name to each photo-identified manatee. Distinctive features were coded following the methods of Beck \& Reid (1995), including the position (e.g. left posterior trunk, right peduncle), type (e.g. scar, mutilation), number (e.g. single, 2 to 3), size (e.g. large, medium), and color (e.g. white, dark). All of these traits were represented as a letter or number in the feature code. Notches on the tail were considered mutilations. Manatees were assigned an 'incomplete status' if only a portion of the body was registered or if only poorquality images (Q3) were available. The photo-ID catalog contained a record of each identified manatee, available information for it, and a set of type specimen images for quick assessment. Each catalog record includes: the individual's code and name; date and place of the first and last sighting; feature code; sex (when possible); age class; identification status (complete or incomplete); and several of the best quality images available depicting recognizable features. A database containing information of photo-identified individuals, i.e. sightings coordinates, time and date, number of manatees encountered, manatee code, and number of images available, was assembled including information from the preliminary sighting database. In this database, we also included the codes of distinctive features, to facilitate the search for individuals by using the letters that compose the code as a filter. Sightings of the same individual on different days were considered re-sightings. Sighting records of the photo-identified manatees were used to construct a cumulative curve of the population at SGC and to calculate the proportion of distinctive manatees within the total sightings (total sightings of photo-identified manatees/total adult manatee sightings).

\section{RESULTS}

Between 2016 and 2017, 103 flights were conducted in Belize: SGC ( $\mathrm{n}=94)$, the mouth of the

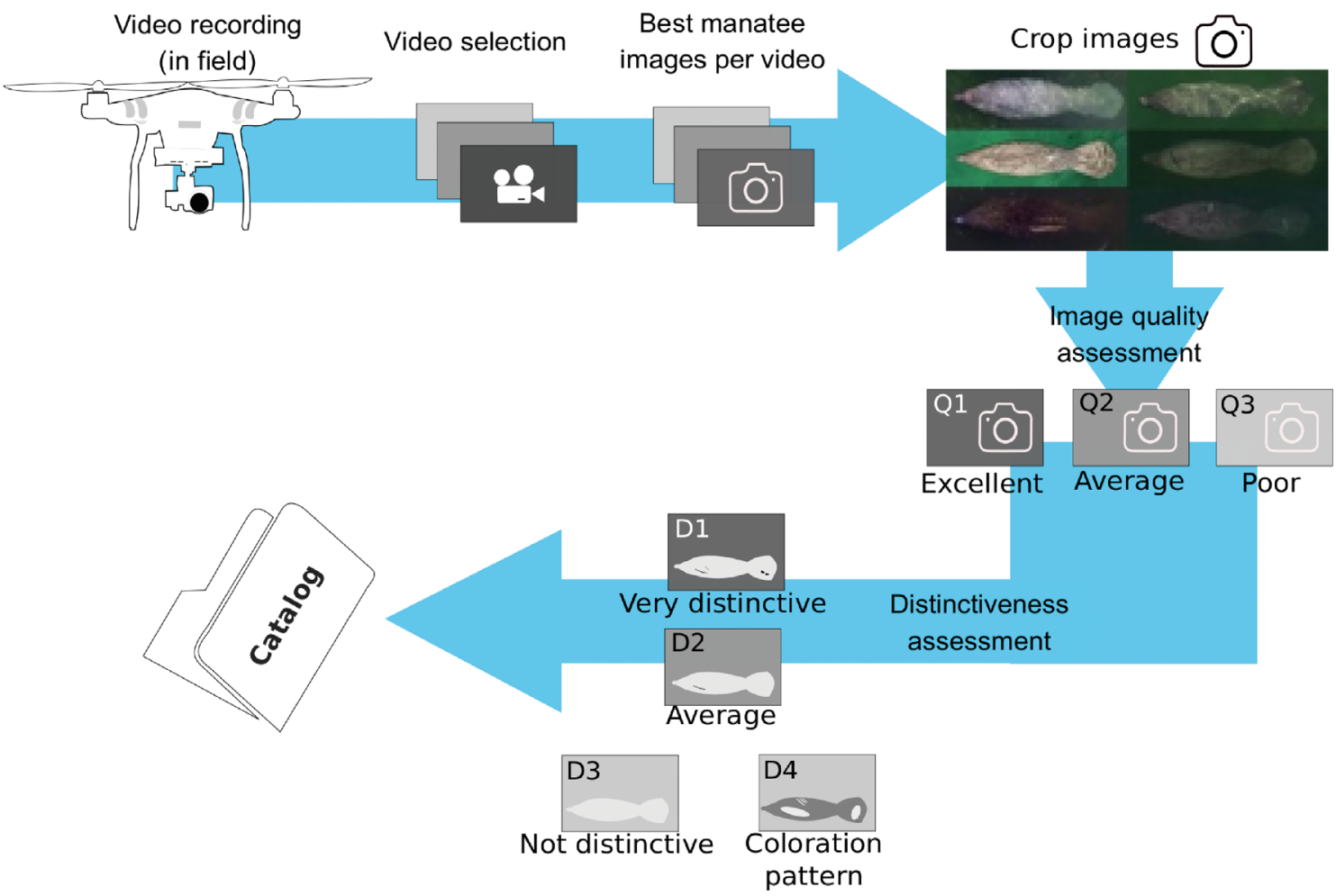

Fig. 3. Workflow for our photo-identification study of Antillean manatees from data acquisition to the creation of a catalog. During video analysis, 1 to 7 images per manatee were selected, rotated, cropped, and coded. All images were scored for image quality and individual distinctiveness. The best available quality images of individuals D1 and D2 were used to create the 
Belize River $(\mathrm{n}=4)$, the Drowned Cayes $(\mathrm{n}=1)$, Man $O^{\prime}$ War Caye $(n=2)$, and Placencia Lagoon $(n=2)$. The review of aerial video (1740 min) resulted in 279 manatee sightings (245 adults, 34 calves). Images extracted from drone videos $(n=466)$ were evaluated for quality and distinctiveness, resulting in the photoID of 17 adult manatees with images that were sufficiently distinctive (D1 and D2, $\mathrm{n}=79$ ) to be included in our catalog (Table 1). The altitude at which the selected images were taken ranged between 5 and $24 \mathrm{~m}$, while the best resolution images (resolution score 2 in image quality scoring) were obtained at lower altitudes (5 to $7 \mathrm{~m}$ ). In general, lower altitudes provided more images of suitable resolution (resolution scores 2 and 4, Fig. 4).

At SGC, sightings of 214 adults and 32 calves were detected in 94 flights (2.6 sightings per flight) from 2016-2017. Photo-identified manatee sightings ( $\mathrm{n}=$ 45) were reported in 39 flights, and the cumulative curve (Fig. 5) did not show an asymptote as new individuals appeared. Considering all adult sightings, the proportion of photo-identified manatees was 0.21 . Fourteen individuals were photo-identified at SGC, 4 of which were re-sighted on different days. The maximum number of these re-sightings was 8 for individual BZ001 (Table 2).

\section{DISCUSSION}

Small multi-rotor drones, when equipped with adequate sensors and operated at adequate altitudes, can be used for photo-ID of Antillean manatees in shallow-water habitats in the Caribbean Sea. Small commercial drones are low-cost and widely available, offering a versatile tool for sirenian management and conservation projects. These systems are equipped with cameras of sufficient resolution for overhead photo-ID at low altitudes $(<30 \mathrm{~m}$, in this study) and can hover in stationary flight, allowing the capture of good quality photographs and videos of surfacing marine mammals (Durban et al. 2015). Therefore, in comparison to other platforms used to collect photographic information of sirenians (from boats, land, or underwater), drones are more effective for remote detection and capture of high-resolution images and videos depicting the entire dorsal view of a sirenian body. Although some features or scars may not be visible from a dorsal view, overhead photos of manatees enable the identification, measurements, and monitoring of most boat-related injuries, which are the most conspicuous features for identification typically found in the manatee dorsum
(Beck et al. 1982, Goldsworthy 2018). Other features important for manatee identification are the notches on the tail, generally visible from a dorsal view.

We advise caution in flying drones near manatees for photo-ID. Data for this study were gathered during flights to test the reactions of Antillean manatees to small drones (Ramos et al. 2018). Of all manatees approached with the drone, $24 \%$ reacted strongly to its vertical approach at a wide range of altitudes (6-104 $\mathrm{m}$ ) by fleeing the area. Unlike most species of marine mammals that show few responses to small drones, typically consisting of short-duration events (Smith et al. 2016, Ramos et al. 2018, Fettermann et al. 2019, Fiori et al. 2020), manatees appear more at risk of disturbance with these systems if approached directly and too closely (Ramos et al. 2018). It is therefore important to evaluate the factors that could trigger a negative behavioral response in manatees, for example, the speed and angle of approach of the drone (Smith et al. 2016). While lower flight altitudes closer to target animals result in higher-resolution imagery (Hodgson et al. 2018), the risk of disturbing animals suggests that careful flight protocols are needed to mitigate disturbances in low-altitude flight (Ramos et al. 2018, Fettermann et al. 2019). Paired with carefully designed protocols, the effects of these systems should be evaluated using behavioral observations of animals exposed to small drone flights at different study sites and in different populations. The impacts on different individuals should be assessed prior to extensive deployment of these systems given that manatees within the same population can vary in their responsivity to small drone flights (Ramos et al. 2018). Additionally, efforts should be made to use

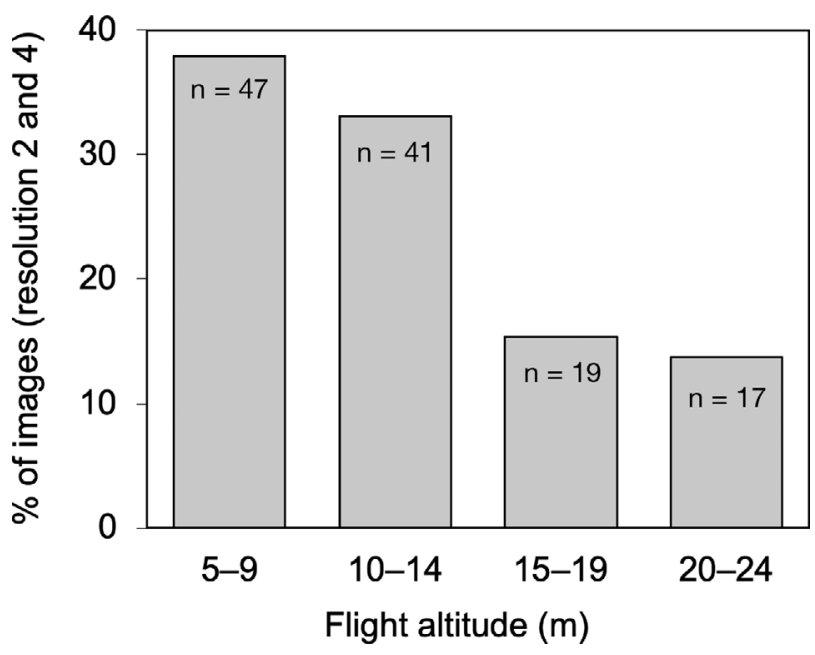

Fig. 4. Percentage of images scored as resolution 2 and 4 (excellent and average, $\mathrm{n}=124$ ) during quality image assessment, related to drone flight altitude 


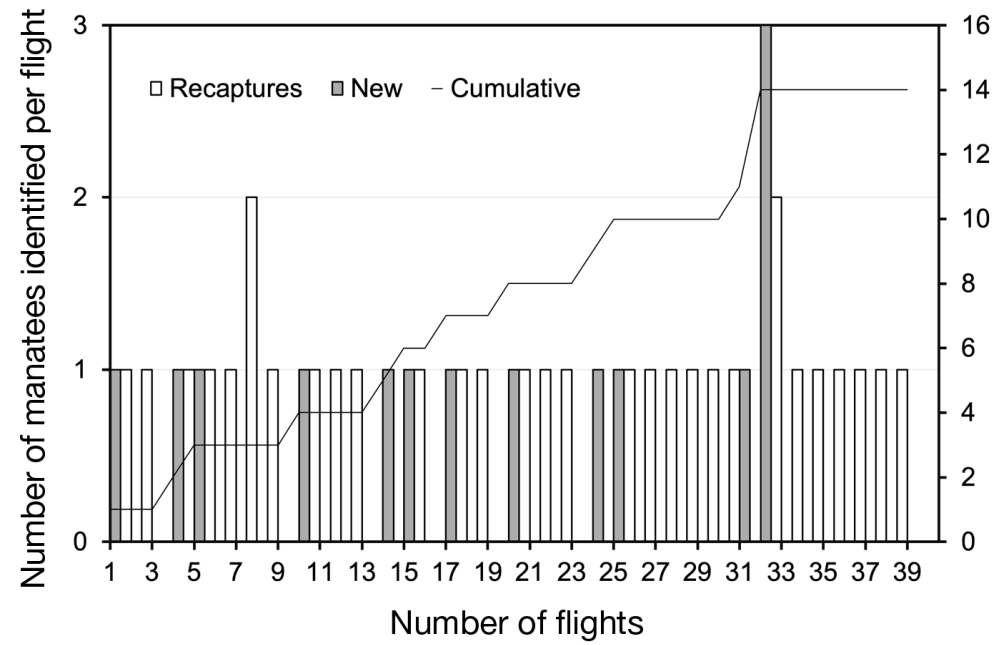

Fig. 5. Cumulative curve of Antillean manatees photo-identified at St. George's Caye, Belize, in 2016 and 2017

systems with reduced noise from the rotors that are equipped with the highest-resolution cameras within budget to minimize the need for lower-altitude flight. Considering that a multirotor produces more noise when changing altitude (Sweeney et al. 2016), we recommend that pilots should minimize aircraft movements when over manatees and advocate for the development of data collection protocols that involve slow aircraft approaches with minimal altitudinal shifts (to reduce noise), reduced movement while animals are at the surface, and maintenance of the highest flight altitudes needed for imagery of sufficient resolution.

Obtaining useful images for photo-ID through this drone-based method can be hindered by environmental factors such as waves or surface ripples, subsurface illumination and shadowing (Mount 2005, Joyce et al. 2018), and minimal ambient light. These factors, individually or combined, reduce the quality of images, causing resolution loss, distortion, and coverage of the manatee body. These environmental factors and their effects are limitations even when using other imaging methods and platforms of observation at the surface. The use of high-resolution aerial video imagery provides more time viewing animals (Ramos et al. 2018), leading to increased opportunities to photograph identifiable features of manatees. However, analyzing images from videos resulted in a loss of some information. For instance, some small marks were better noticed in videos compared to the extracted images because the movement helped the reviewers to differentiate little features from shadows, waves and other visual distortions. Thus, future applications of drone-based photoidentification should evaluate the costs and benefits
$£$ of capturing aerial video relative to still imagery.

Difficulties associated with photoidentification of manatees such as a lack of distinctive marks on some individuals limit the effectiveness of this method (Beck \& Clark 2012). Skin characteristics other than scars include impermanent and subtle features like minor skin abrasions (D3) and coloration patterns (D4). The body of an Antillean manatee is gray, but because of its low mobility during resting or feeding (Violante-Huerta \& Suárez-Morales 2016), individuals often appear with brownish, greenish, blackish, or even whitish patches from an accumulation of sediments and/or epibionts on their surfaces (Violante-Huerta et al. 2017). The presence of organisms covering manatees (parasites, algae, commensal associates, etc.) varies substantially between individuals and between habitat types (Stamper \& Bonde 2012) and the duration of these kinds of patterning is unknown. Due to the uncertainty of their duration, D3 and D4 features are not suitable for entering into a photo-ID catalog, but those characteristics could be used for a limited range and time using a suitable image quality threshold (Urian et al. 2015). Subtle features (D3) like scratches may only be useful for identification over weeks or

Table 2. Individual adult Antillean manatees identified in this study. Number of sightings of individuals considering different days. Feature codes are described in Section 2.4. F: female; U: unknown; SGC: St. George's Caye; BZR: Belize River

\begin{tabular}{|llllll|}
\hline ID & Sex & Area & No. of \\
sightings & Feature & Feature \\
type & codes \\
\hline \multicolumn{7}{r}{ BZ001 } & U & SGC & 8 & Scar & SDA1LGL \\
BZ002 & U & SGC & 7 & Scar & SDX1SWL \\
BZ003 & U & SGC & 1 & Scar & SRB1MWL, SDX1MWL \\
BZ004 & F & SGC & 1 & Scar & SDC3SGL \\
BZ005 & F & SGC & 1 & Scar & SLX2SGL, SRX1SGL \\
BZ006 & U & SGC & 1 & Scar & SLD1SGL, SDX3SGL \\
BZ007 & U & SGC & 1 & Scar & SLC2SWL \\
BZ008 & U & SGC & 1 & Scar & SRC2SWB \\
BZ009 & U & BZR & 1 & Scar & SDY2SGL \\
BZ010 & U & BZR & 1 & Scar & SLC1LWL, SDC3LWL \\
BZ011 & U & BZR & 1 & Scar & SDC2MWL \\
BZ012 & F & SGC & 3 & Scar & SDB2SWB \\
BZ013 & U & SGC & 3 & Scar & SLB1SWL \\
BZ014 & U & SGC & 1 & Mutilation & MRX1S, MRY1S \\
BZ015 & U & SGC & 1 & Mutilation & MRY1S \\
BZ016 & U & SGC & 1 & Scar & SDB1MWB \\
BZ017 & U & SGC & 1 & Mutilation & MLY1S \\
\hline
\end{tabular}


months; for example, Anderson (1995) observed that minor skin abrasions persisted for at least $2 \mathrm{wk}$ in dugongs. Similarly, the adult manatee 'George' (BZ001) identified at SGC was distinguished from other manatees using subtle features (D3) for $10 \mathrm{~d}$ before it acquired a large distinctive scar (Ramos et al. 2017). Subtle features could be included in a different catalog for monitoring manatees over the short-term (days to weeks) but are unlikely to be useful over months and years due to shifts in skin coverage over seasons and as manatees travel between fresh and salt water habitats.

At SGC, the non-asymptotic nature of the discovery curve (Fig. 5) suggests that the time frame and spatial range of our photo-ID effort were insufficient to identify the entire population (Karczmarski et al. 1999). Estimates of population size by capture-recapture analysis are not yet feasible with small drone flights, and given the large home range of individual Antillean manatees (Castelblanco-Martínez et al. 2012), identifying a large portion of the population would require flights throughout their range. However, dronebased photo-ID of manatees could facilitate studies on individual life history, site fidelity, and habitat use in locations, like SGC, with good visibility and the regular occurrence of manatees. For instance, BZ001 and BZ002 were repeatedly sighted in the SGC area, providing clues on their life history and fine-scale habitat use. Likewise, repeated observation of identified individuals enables the tracking of several aspects of animal health condition, for example, fine-scale temporal patterns in scar acquisition and healing (Ramos et al. 2017, Goldsworthy 2018), and impacts of repeated disturbance (Ramos et al. 2018). Furthermore, obtaining high quality images with reliable aircraft altitude data opens up the possibility for photogrammetric methods of measuring manatee body size (e.g. Flamm et al. 2000) that can be applied to assess health condition and age class of individuals.

Data gathered from drone-based studies of manatees have the potential to provide valuable information on the occurrence of manatees and can facilitate the identification of threats to their well-being. Scars on manatees can be the consequence of vessel collisions, entanglement in fishing gear, fungal infections, and cold lesions (Beck \& Clark 2012). Since the current main cause of manatee mortality in Belize is hypothesized to be boat collisions (CastelblancoMartínez et al. 2018), determining the proportion and severity of scars in manatees from Belize could serve as an important tool to monitor the most significant local threat to this population. For example, the size, shape, and location of scars can be used to determine the type of propeller that caused the wound (Beck et al. 1982), how frequently manatees are struck by boats (Goldsworthy 2018), and which individuals within a population are more vulnerable to boat collisions. Similarly, improved detection of and data collection on manatees in specific areas can be used to advocate for increased animal protection to reduce watercraft collisions with manatees. For example, drone-based detections and identification of manatees at SGC was successfully used to advocate for the establishment of a 'no-wake zone' across the channels along the leeward side of SGC that went into effect in 2017 (Ramos et al. 2017).

Photo-ID of Antillean manatees has great potential in the Caribbean due to its clear waters, facilitating this study and previous photo-ID efforts in Belize (e.g. Self-Sullivan 2007, Arce 2012). Belize has a relative high density of manatees and a high probability of encounters compared to other areas in the subspecies distribution (Quintana-Rizzo \& Reynolds 2010). However, manatees often use turbid areas such as the Belize River (one of our study sites), where clear images of manatees were difficult to collect because of the high levels of turbidity and rarity of manatees exposing their bodies at the surface. Overall, compared to other platforms, drones are more effective in these situations because during video recording, they can capture overhead views of the exact moment when a manatee surfaces.

Future studies using drones to identify and track the movements and behavior of manatees across the coast of Belize and Mexico require standardized and rigorous methods for data collection. The novel use of drones for manatee photo-ID will benefit from predictable advancements in technology and rigorous applications of methodology. Improvements to system components like camera resolution and frame rate, increased battery life, reduced rotor noise, and accuracy of sensors (e.g. GPS, altimeter) at lower costs will dramatically enhance the use of dronebased imagery for manatee photo-ID. Such improvements would facilitate photogrammetric measurements of manatee body size while flying at higher altitudes and at lower noise levels, with reduced likelihood of disturbance to target species.

We propose that our method and cataloging system should be considered as another tool for manatee monitoring in order to provide long-term, reliable information on wild populations. For example, the Manatee Individual Photo-identification System has compiled photographs of Florida manatees since the late 1970s and has generated a catalog containing information on more than 2000 individuals (Beck \& 
Reid 1995, Beck \& Clark 2012). This information has enabled studies on the biology, reproduction, conservation status, population structure, and dynamics of Florida manatees, which has been extremely useful in making management decisions. Furthermore, radiotagging studies of manatees captured in the Caribbean revealed long-distance movements between Mexico, Belize, and Guatemala (Castelblanco-Martínez et al. 2013), suggesting that a regional approach is needed for monitoring the subspecies. Standardizing the coding for individuals and markings across regions will enable comparisons of photo-ID catalogs. Hence, our protocol could be implemented over the long term and expanded to other areas in the Caribbean to improve the Antillean manatee monitoring in the region.

Acknowledgements. We thank ECOMAR for hosting E.A.R. at their field station on St. Georges Caye in Belize and for collaborating on this research; SEE Turtles and their volunteers for helping start this project and supporting our data collection each year; and the anonymous reviewers for their helpful comments and recommendations, which greatly improved and enriched this manuscript. This research and data collection were conducted under permits granted to E.A.R. from the Belize Department of Civil Aviation (Ref. No. AO/56/16[47]), the Belize Fisheries Department (Ref. No. 000031-17, 000010-15), the Belize Forest Department (Ref. No. WL/1/1/16[28], W/L2/1/17[07]), and the Belize Public Utilities Commission (Ref. No. 156/161).

\section{LITERATURE CITED}

Ackerman BB (1995) Aerial surveys of manatees: a summary and progress report. In: O'Shea TJ, Ackerman BB, Percival HF (eds) Population biology of the Florida manatee. Inf Tech Rep 1. National Biological Service, Washington, DC, $p$ 13-33

Alves MD, Kinas PG, Marmontel M, Borges JCG, Costa AF, Schiel N, Araújo ME (2016) First abundance estimate of the Antillean manatee (Trichechus manatus manatus) in Brazil by aerial survey. J Mar Biol Assoc UK 96:955-966

Anderson PK (1995) Scarring and photoidentification of dugongs (Dugong dugon) in Shark Bay, Western Australia. Aquat Mamm 21:205-211

Arce N (2012) Conservation of manatees in the area of the Swallow Caye Wildlife Sanctuary: population study. Report for International Ecology course. ECOSUR and Université de Sherbrooke, Quebec

Auil N (1998) Belize manatee recovery plan. Coastal Zone Management Authority and Institute, Belize City

Bacchus MLC, Dunbar SG, Self-Sullivan C (2009) Characterization of resting holes and their use by the Antillean manatee (Trichechus manatus manatus) in the Drowned Cayes, Belize. Aquat Mamm 35:62-71

Beck C, Clark A (2012) Individual identification of sirenians. In: Hines EM, Reynolds J III, Aragones LV, MignucciGiannoni AA, Marmontel M (eds) Sirenian conservation: issues and strategies in developing countries. University Press of Florida, Gainesville, FL, p 133-138
Beck CA, Reid JP (1995) An automated photo-identification catalog for studies of the life history of the Florida manatee. In: O'Shea TJ, Ackerman BB, Percival HF (eds) Population biology of the Florida manatee. Inf Tech Rep 1. National Biological Service, Washington, DC, p 56-62

Beck CA, Bonde RK, Rathbun GB (1982) Analyses of propeller wounds on manatees in Florida. J Wildl Manag 46:531-535

* Bengtson JL, Hiruki-Raring LM, Simpkins MA, Boveng PL (2005) Ringed and bearded seal densities in the eastern Chukchi Sea, 1999-2000. Polar Biol 28:833-845

* Castelblanco-Martínez DN, Nourisson C, Quintana-Rizzo E, Padilla-Saldivar JA, Schmitter-Soto JJ (2012) Potential effects of human pressure and habitat fragmentation on population viability of the Antillean manatee Trichechus manatus manatus: a predictive model. Endang Species Res 18:129-145

* Castelblanco-Martínez DN, Padilla-Sáldivar J, HernándezArana HA, Slone D, Reid J, Morales-Vela B (2013) Movement patterns of Antillean manatees in Chetumal Bay (Mexico) and coastal Belize: a challenge for regional conservation. Mar Mamm Sci 29:E166-E182

Castelblanco-Martínez DN, Galves J, Ramos E, Searle L, Niño-Torres CA, Padilla Saldívar JA (2018) A decade of manatee mortality along the Caribbean coast of Belize and Mexico shows a dramatic increase in watercraft related deaths. Proc XXXVI Reunión Internacional para el Estudio de los Mamíferos Marinos, Tabasco, México

Cho L (2005) Marine protected areas: a tool for integrated coastal management in Belize. Ocean Coast Manag 48: 932-947

Christiansen F, Dujon AM, Sprogis KR, Arnould JP, Bejder L (2016) Noninvasive unmanned aerial vehicle provides estimates of the energetic cost of reproduction in humpback whales. Ecosphere 7:e01468

Colefax AP, Butcher PA, Kelaher BP (2018) The potential for unmanned aerial vehicles (UAVs) to conduct marine fauna surveys in place of manned aircraft. ICES J Mar Sci 75:1-8

* Domínguez-Sánchez CA, Acevedo-Whitehouse KA, Gendron D (2018) Effect of drone-based blow sampling on blue whale (Balaenoptera musculus) behavior. Mar Mamm Sci 34:841-850

* Durban J, Fearnbach H, Barrett-Lennard L, Perryman W, Leroi D (2015) Photogrammetry of killer whales using a small hexacopter launched at sea. J Unmanned Vehicle Syst 3:131-135

* Durban JW, Moore MJ, Chiang G, Hickmott LS and others (2016) Photogrammetry of blue whales with an unmanned hexacopter. Mar Mamm Sci 32:1510-1515

Ely GF, Saavedra R, Davila E, Casteblanco-Martínez D, Barreto A (2017) Evaluation of photo-identification on the Amazonian manatee Trichechus inunguis. Proc VIII Encontro Nacional sobre Conservação e Pesquisa de Mamíferos Aquáticos, Natale, Brazil

F Fettermann T, Fiori L, Bader M, Doshi A, Breen D, Stockin KA, Bollard B (2019) Behaviour reactions of bottlenose dolphins (Tursiops truncatus) to multirotor Unmanned Aerial Vehicles (UAVs). Sci Rep 9:8558

Fiori L, Martinez E, Bader MKF, Orams MB, Bollard B (2020) Insights into the use of an unmanned aerial vehicle (UAV) to investigate the behavior of humpback whales (Megaptera novaeangliae) in Vava'u, Kingdom of Tonga. Mar Mamm Sci 36:209-223

Flamm RO, Owen ECG, Owen CFW, Wells RS, Nowacek D (2000) Aerial videogrammetry from a tethered airship to 
assess manatee life-stage structure. Mar Mamm Sci 16: $617-630$

Friday N, Smith TD, Stevick PT, Allen J (2000) Measurement of photographic quality and individual distinctiveness for the photographic identification of humpback whales, Megaptera novaeangliae. Mar Mamm Sci 16: 355-374

Goldsworthy L (2018) Regionalization of scar patterns on the Florida manatee (Trichechus manatus latirostris) observed at Harbor Branch Oceanographic Institute, Florida. MSc thesis, Florida Atlantic University, Boca Raton, FL

Gope C, Kehtarnavaz N, Hillman G, Würsig B (2005) An affine invariant curve matching method for photo-identification of marine mammals. Pattern Recognit 38: 125-132

Hartman DS (1979) Ecology and behavior of the manatee (Trichechus manatus) in Florida. Am Soc Mammal Spec Publ Ser 5:1-153

Hodgson A, Kelly N, Peel D (2013) Unmanned aerial vehicles (UAVs) for surveying marine fauna: a dugong case study. PLOS ONE 8:e79556

Hodgson A, Peel D, Kelly N (2017) Unmanned aerial vehicles for surveying marine fauna: assessing detection probability. Ecol Appl 27:1253-1267

*Hodgson JC, Mott R, Baylis SM, Pham TT and others (2018) Drones count wildlife more accurately and precisely than humans. Methods Ecol Evol 9:1160-1167

Joyce K, Duce S, Leahy S, Leon J, Maier S (2018) Principles and practice of acquiring drone-based image data in marine environments. Mar Freshw Res 70:952-963

Karczmarski L, Winter PE, Cockcroft VG, Mclachlan A (1999) Population analyses of Indo-Pacific humpback dolphins Sousa chinensis in Algoa Bay, Eastern Cape, South Africa. Mar Mamm Sci 15:1115-1123

Keller CA, Ward-Geiger LI, Brooks WB, Slay CK, Taylor CR, Zoodsma BJ (2006) North Atlantic right whale distribution in relation to sea-surface temperature in the southeastern United States calving grounds. Mar Mamm Sci 22:426-445

Kendall WL, Langtimm CA, Beck CA, Runge MC (2004) Capture-recapture analysis for estimating manatee reproductive rates. Mar Mamm Sci 20:424-437

Koski WR, Gamage G, Davis AR, Mathews T, LeBlanc B, Ferguson SH (2015) Evaluation of UAS for photographic re-identification of bowhead whales, Balaena mysticetus. J Unmanned Vehicle Syst 3:22-29

* Langtimm CA, O'Shea TJ, Pradel R, Beck CA (1998) Estimates of annual survival probabilities for adult Florida manatees (Trichechus manatus latirostris). Ecology 79:981-997

* Langtimm CA, Beck CA, Edwards HH, Fick-Child KJ, Ackerman BB, Barton SL, Hartley WC (2004) Survival estimates for Florida manatees from the photo-identification of individuals. Mar Mamm Sci 20:438-463

Marsh H (1995) The life history, pattern of breeding, and population dynamics of the dugong. In: O'Shea T, Ackerman BB, Percival F (eds) Population biology of the Florida manatee. Inf Tech Rep 1. National Biological Service, Washington, DC, p 75-83

Morales-Vela B, Padilla-Saldivar JA, Mignucci-Giannoni AA (2003) Status of the manatee (Trichechus manatus) along the northern and western coasts of the Yucatan Peninsula, Mexico. Caribb J Sci 39:42-49

Mount R (2005) Acquisition of through-water aerial survey images. Photogramm Eng Remote Sensing 71:1407-1415

* Panigada S, Lauriano G, Burt L, Pierantonio N, Donovan G
(2011) Monitoring winter and summer abundance of cetaceans in the Pelagos Sanctuary (northwestern Mediterranean Sea) through aerial surveys. PLOS ONE 6: e22878

Pomeroy P, O'Connor L, Davies P (2015) Assessing use of and reaction to unmanned aerial systems in gray and harbor seals during breeding and molt in the UK. J Unmanned Vehicle Syst 3:102-113

Quintana-Rizzo E, Reynolds JI (2010) Regional management plan for the West Indian manatee (Trichechus manatus). CEP Tech Rep. Caribbean Environment Programme, United Nations Environment Programme, Kingston

Ramos EA, Castelblanco-Martínez DN, Landeo-Yauri S, Niño-Torres C, Magnasco M, Reiss D (2017) Small drones: a tool to study, monitor, and manage free-ranging Antillean manatees in Belize and Mexico. Sirenews 67:13-16

Ramos EA, Maloney BM, Magnasco MO, Reiss D (2018) Bottlenose dolphins and Antillean manatees respond to small multi-rotor unmanned aerial systems. Front Mar Sci 5:316

Rathbun GB, Reid JP, Bonde R, Powel JA (1995) Reproduction in free-ranging Florida manatees. In: O'Shea TJ, Ackerman BB, Percival HF (eds) Population biology of the Florida manatee. Inf Tech Rep 1. National Biological Service, Washington, DC, p 135-156

* Reid JP, Rathbun GB, Wilcox JR (1991) Distribution patterns of individually identifiable West Indian manatees (Trichechus manatus) in Florida. Mar Mamm Sci 7: 180-190

Rosel PE, Hohn AA, Mullin K, Garrison LP and others (2011) Photo-identification capture-mark-recapture techniques for estimating abundance of bay, sound and estuary populations of bottlenose dolphins along the US East Coast and Gulf of Mexico, a workshop report. NOAA Tech Memo NMFS-SEFSC 621. NOAA, NMFS, SEFSC, Lafayette, LA

Rycyk AM, Deutsch CJ, Barlas ME, Hardy SK, Frisch K, Leone EH, Nowacek DP (2018) Manatee behavioral response to boats. Mar Mamm Sci 34:924-962

Self-Sullivan C (2007) Non-lethal boat scars on manatees in Belize as a tool for evaluation of a Marine Protected Area preliminary results. Proc Gulf Caribb Fish Inst 59:465-470

Self-Sullivan C, Mignucci-Giannoni A (2008) Trichechus manatus ssp. manatus. The IUCN Red List of Threatened Species 2008: e.T22105A9359161. http://dx.doi.org/ 10.2305/IUCN.UK.2008.RLTS.T22105A9359161.en

Shawky AM, Sallam WS, Alwany MA, Mohammad DA, Mohamed SZ (2017) Photo identification of dugongs in Marsa Alam and Wadi El Gemal National Park, Egyptian coast of the Red Sea. Al Azhar Bull Sci 28:1-10

Smith CE, Sykora-Bodie ST, Bloodworth B, Pack SM, Spradlin TR, LeBoeuf NR (2016) Assessment of known impacts of unmanned aerial systems (UAS) on marine mammals: data gaps and recommendations for researchers in the United States. J Unmanned Vehicle Syst $4: 31-44$

Stamper MA, Bonde RK (2012) Health assessment of captive and wild-caught West Indian manatees (Trichechus manatus). In: Hines E, Reynolds JE III, Aragones L, Mignucci-Giannoni A, Marmontel M (eds) Sirenian conservation: issues and strategies in developing countries. University Press of Florida, Gainesville, FL, p 139-147

Sweeney KL, Helker VT, Perryman WL, LeRoi DJ, Fritz LW, Gelatt TS, Angliss RP (2016) Flying beneath the clouds at the edge of the world: using a hexacopter to supplement 
abundance surveys of Steller sea lions (Eumetopias jubatus) in Alaska. J Unmanned Vehicle Syst 4:70-81

Torres LGT, Nieukirk S, Lemos L, Chandler T (2018) Drone up! Quantifying whale behavior from a new perspective improves observational capacity. Front Mar Sci 5:319

Urian KW, Hohn AA, Hansen LJ (1999) Status of the photoidentification catalog of coastal bottlenose dolphins of the western North Atlantic. Report of a workshop of catalog contributors. US Department of Commerce, National Oceanic and Atmospheric Administration, National Marine Fisheries Service, Beaufort, NC

Urian K, Gorgone A, Read A, Balmer B and others (2015) Recommendations for photo identification methods used

Editorial responsibility: Helene Marsh,

Townsville, Queensland, Australia in capture recapture models with cetaceans. Mar Mamm Sci 31:298-321

* Violante-Huerta M, Suárez-Morales E (2016) The epiphytic copepod Metis holothuriae (Edwards, 1891) (Harpacticoida), a new epibiont of the Caribbean manatee. Crustaceana 89:639-644

*Violante-Huerta M, Díaz-Gamboa R, Ordóñez-López U (2017) Antillean manatee Trichechus manatus manatus (Sirenia: Trichechidae) as a motile ecosystem of epibiont fauna in the Caribbean Sea, Mexico. Therya 8:273-276

* Würsig B, Würsig M (1977) The photographic determination of group size, composition, and stability of

Submitted: February 4, 2019; Accepted: November 5, 2019

Proofs received from author(s): January 17, 2020 